\title{
Desafios das Cooperativas de Agricultores Familiares: o caso do Assentamento Rio Paraíso
}

\author{
Décio Lauri Sieb ${ }^{1}$
}

\begin{abstract}
Resumo
Este trabalho mostra a importância e o potencial do cooperativismo para facilitar o acesso dos agricultores familiares aos mercados. Utilizando a abordagem da nova economia institucional (NEI), o estudo tem como objetivo analisar se a Cooperativa Mista Agropecuária Rio Doce (COPARPA) está conseguindo responder as expectativas dos agricultores do assentamento Rio Paraíso, no município de Jataí - Goiás, no ano de 2014. A maioria dos agricultores apontou a cooperativa como canal preferencial para acesso aos mercados, especialmente os institucionais (Biodiesel, Programa de Aquisição de Alimentos - PAA e Programa Nacional de Alimentação Escolar - PNAE). A análise evidencia a importância destas políticas públicas para estímulo da produção e comercialização, mas ao mesmo tempo revela a fragilidade e dependência da cooperativa em relação a continuidade destas políticas públicas.
\end{abstract}

Palavras-chave: Agricultura familiar. Cooperativas. Comercialização e mercados.

\begin{abstract}
This paper shows the importance and potential of cooperatives to facilitate family farmers' access to markets. Using the New Institutional Economics (NIS) approach, the study aims to analyze whether the Cooperativa Mista Agropecuária Rio Doce (COPARPA) is meeting the expectations of the farmers of the Rio Paraiso settlement, in the municipality of Jatai - Goiás, in the year 2014. Most farmers pointed to the cooperative as a preferred channel to access to markets, especially the institutional (Biodiesel, PAA and PNAE). The analysis highlights the importance of public policies to stimulate the production and marketing, but at the same time reveals the weakness and dependence of the cooperative regarding the continuation of these public policies.
\end{abstract}

Keywords: Family farming. Cooperative. Commercialization and markets.

\section{Introdução}

A agricultura familiar tem perseverado e resistido ao longo da história, apesar dos desafios enfrentados e das previsões leninistas da sua extinção. Apesar da permanência da agricultura familiar nas sociedades modernas, parcela importante sobrevive em condições próximas à pobreza. Um dos seus principais desafios para a reprodução e continuidade da agricultura familiar está na comercialização. A produção em pequena escala, a distância dos principais centros consumidores, as condições precárias das estradas e a baixa disponibilidade de meios de transporte são fatores que tem contribuído para dificultar o

\footnotetext{
1 Mestre em Agronegócio. Assessor técnico de política agrícola da Confederação Nacional dos Trabalhadores na Agricultura (Contag).decio@contag.org.br
} 
acesso ao mercado. Por outro lado, a pressão do mercado e a concorrência de outros atores que atuam nas cadeias produtivas, combinados com a assimetria de informações entre os agricultores, potencializam as dificuldades de comercialização.

O Censo Agropecuário de 2006 do Instituto Brasileiro de Geografia e Estatística (IBGE,2015) informa que há no Brasil 4,3 milhões de unidades familiares, sendo que os assentamentos respondiam por $12 \%$ do total de estabelecimentos e $9 \%$ do total da área (MARQUES; GROSSI; FRANCA, 2012). Guanziroli, Di Sabbato e Buainain (2012), a partir deste Censo, aponta que dessas famílias, próximo a quatro milhões auferem uma renda monetária líquida agropecuária entre $\mathrm{R} \$ 255,00$ a $\mathrm{R} \$ 3.725,00$ por ano. $\mathrm{O}$ autor indica como principais fatores para esse desempenho econômico pouco expressivo o perfil de produção dos agricultores familiares e a maneira de acesso ao mercado. Por outro lado, aponta que a realidade do mercado, ou seja, os fatores gerais do jogo das forças de mercado existentes não são favoráveis aos agricultores familiares, bem como as políticas públicas voltadas para este segmento da sociedade são deficitárias no tocante a produção e comercialização.

Schneider e Cassol (2013) ressaltam que para 2,5 milhões de agricultores familiares a principal fonte de recursos financeiros é proveniente das atividades agropecuárias, representando, em média 91\% do total das receitas obtidas. Botelho Filho (2005) argumenta que a saída da pobreza pelo viés agrícola não está somente na produção, mas especialmente em uma boa comercialização. Entretanto, para um conjunto expressivo de agricultores a exclusão social é quase uma certeza, considerando o cenário e as condições atuais dos mercados agropecuários.

Para Claro e Santos (1998) a forma pela qual os agricultores interagem, bem como, a própria existência das organizações (associações, cooperativas) são reflexos do ambiente institucional em que atuam. Os autores apontam que diante da dinâmica atual do mercado há necessidade constante de fortalecimento dos agricultores, e neste sentido ressaltam a importância das soluções cooperativas e coletivas para melhorar o desempenho dos atores envolvidos nas transações. A criação e a efetivação das políticas públicas de proteção e estímulo à comercialização para os produtos da agricultura familiar, no caso as compras institucionais, podem ser determinantes. Botelho Filho (2005) sugere que as novas tecnologias e mercados mais cativos propiciam oportunidades para organizações de pequeno porte e a ação coletiva entre os assentados da reforma agrária, possibilitando a 
economia dos custos de transação e do processo de comercialização. Contudo, não se deve esquecer que os mecanismos de mercado são por natureza seletiva.

Diante dos desafios expostos, principalmente relativo às dificuldades de acesso aos mercados, o presente estudo tem como principal objetivo analisar se a Cooperativa Mista Agropecuária Rio Doce (COPARPA) está conseguindo responder às expectativas dos agricultores do assentamento Rio Paraíso, no tocante ao acesso ao mercado. Para responder à problemática descrita acima foram levantadas duas hipóteses. A primeira sugere que a maioria dos agricultores familiares comercializa seus produtos por meio da cooperativa, por entenderem ser a melhor opção, para fins de potencializar em condições mais favoráveis de acesso ao mercado. A segunda supõe que os mercados institucionais são mecanismos que estimulam e fortalecem a ação coletiva por meio de organização socioeconômica dos agricultores familiares. A pesquisa focou na verificação da importância dada pelos agricultores à cooperativa para acessar o mercado, e se a cooperativa proporciona ou não melhores condições de acesso ao mercado, bem como sua agilidade no acesso aos mercados institucionais.

O presente trabalho está dividido em cinco seções, além desta introdução, onde se procura contextualizar e problematizar o acesso ao mercado. A segunda seção apresenta alguns referenciais da nova economia institucional tendo como base os estudos de Williamson (1975) que analisa a economia a partir das instituições. Na busca de respostas ao problema exposto com objetivo de comprovar ou refutar as hipóteses sugeridas, optou-se por uma pesquisa quanti-qualitativa. Os procedimentos metodológicos e técnicas de pesquisa em relação ao trabalho estão descritos na terceira seção, onde são detalhadas as etapas adotadas e os procedimentos para a realização dos trabalhos de campo. A abordagem metodológica levou em consideração o tipo de pesquisa realizada, que no presente trabalho trata-se de um estudo de caso. A quarta seção apresenta a análise e interpretação de dados referente à pesquisa realizada junto aos agricultores familiares do assentamento Rio Paraíso, seguido pelas considerações finais.

\section{A abordagem da economia institucional como possibilidade de análise dos mercados agropecuários}

Para a Nova Economia Institucional (NEI), a economia é vista como uma teoria de escolha sujeita a entraves e a mudança no preço tendo a influência das instituições. De 
acordo com North (1990), um dos pensadores da NEI, as instituições reproduzem as regras do jogo de uma sociedade, que consistem em restrições informais e regras formais. Um dos objetivos das instituições é reduzir as incertezas no processo de trocas. Para a NEI as pessoas não são insensíveis ou indiferentes ao risco (SLANGEN, LOCKS; SLANGEN, 2008). Os principais estudiosos neste campo são Ronald Coase, Oliver Williamson e Douglas North, tendo como conceitos chave: custo de transação e os direitos de propriedade. Para North (1990), o mercado é uma mescla de instituições, em que algumas aumentam sua eficiência, outras diminuem. Para Coase (1988), o mercado é uma instituição social o que facilita a troca. A estrutura física, regras e regulamentos são elaborados para reduzir os custos de troca. O autor entende que o mercado depende de regras claras e aplicação de sanções do Estado, como também este pode definir que tipos de produtos são apropriados para a troca.

A tese da NEl, originada a partir de Oliver Williamson, vê a economia a partir das instituições (SLANGEN, LOCKS; SLANGEN, 2008). De acordo com Williamson (1975) a NEI procura aprofundar a análise do ambiente institucional e organizacional onde as organizações estão inseridas. O objetivo, nesse caso é estudar e criar arranjos institucionais que venham oferecer uma diferenciação às estruturas e o comportamento das firmas, as quais serão sentidos no desempenho da mesma. A eficiência do sistema econômico em geral depende do que ocorre nas organizações. A coordenação consiste na construção institucional que envolve uma rede de atores os quais buscam criar condições que permitam a sociedade o acesso a produtos e serviços demandados. A coordenação adotada para o agronegócio se expressa no “... resultado da ação de distintos mecanismos que permitem suprir as necessidades dos consumidores finais" (ZYLBERTAJN, 1995, p. 131).

Helfand e Pereira (2012) apontam que os principais desafios da agricultura familiar são os altos custos de transação no acesso a insumos e na venda de sua produção. Os autores afirmam que existem diversas formas de coordenação (vertical, horizontal, complementar e focal) que podem facilitar tanto a participação no mercado como a prestação de serviços para a agricultura familiar. A possibilidade de realizar transações repetidas ao longo de uma cadeia de abastecimento é, muitas vezes, suficiente para reduzir os custos de transação associados à qualidade do produto ou ao risco de inadimplência. (HELFAND; PEREIRA, 2012, p. 151). Contudo, há necessidade de os estabelecimentos familiares avançarem nas estratégias coletivas de inserção no mercado, pois segundo 
Botelho Filho e Valente (2006), o processo de concentração e integração vertical nas cadeias produtivas lança um desafio que é buscar estratégias e mecanismos que garantam a sobrevivência dos agricultores familiares, e impeçam a sua exclusão do mercado e dos processos econômicos. Dessa forma, a visão de Schneider e Cassol (2013) afirma que as políticas públicas de estímulo à comercialização, apesar dos recursos orçamentários limitados, são importantes mecanismos para o processo de promoção socioeconômica da agricultura familiar:

[...] há necessidade de as políticas públicas para a agricultura familiar aprofundar o apoio aos processos de organização da produção e apoio à construção de mercados. Os agricultores familiares precisam de mais e melhores mercados, para que não fiquem dependentes e vulneráveis dos canais de venda da produção agropecuária que são dominados e oligopolizados pelas grandes cadeias do setor agroalimentar (SCHNEIDER; CASSOL, 2013, p. 63).

Para aperfeiçoar e ampliar as condições produtivas e de inserção no mercado, Buainain et al. (2003) indicam que a adoção de políticas públicas voltadas para a agricultura familiar é fundamental. Políticas públicas de apoio à comercialização que estimulassem a agregação de valor e a venda direta dos produtos para os mercados consumidores se tornaram realidade, para agricultura familiar, a partir de 2003 com o surgimento do Programa de Aquisição de Alimentos (PAA). Por outro lado, Gomes Junior e Botelho Filho (2009), ressaltam que a participação da agricultura familiar no atendimento ao mercado institucional ainda está bem aquém em relação a sua participação percentual no fornecimento de alimentos para o atendimento ao consumo interno do Brasil. Dentre os motivos destacam a dificuldade desse público se organizar de forma associativa, adquirindo o mínimo de escala e regularidade para o abastecimento do mercado coletivamente. Devese considerar ainda, o papel da assistência técnica e da extensão rural em preparar os agricultores familiares a produzir conforme as demandas do mercado, salientado os aspectos nutricionais e sanitários.

O cooperativismo tem mostrado ser uma forma socioeconômica atraente e promissora para suprir o papel institucional no processo de comercialização. No entanto, o êxito social e econômico da cooperativa depende da capacidade efetiva dessa organização em prestar serviços que atendam aos anseios dos associados. Para Benecke (1980) a consecução dos objetivos econômicos exige a racionalização dos processos nas atividades produtivas para 
enfrentar a concorrência nos mercados. Para o autor a cooperativa cria condições para a "racionalização de processos produtivos, reduzindo-se os custos que são ou seriam necessários em caso de uma operação individual" (BENECKE, 1980, p. 139). Zylberstajn (2005) observa que um dos fatores de análise na cooperativa é sua capacidade de intervenção no mercado. O autor, com base em Cook (1995) e Bialoskorski Neto (2005) ressalta que há, no Brasil, cinco problemas comumente enfrentados pelas cooperativas, sendo eles:

a) De horizonte - os projetos de longo prazo encontram dificuldades de aprovação, pois é comum os cooperados terem interesses de curto prazo, pois em geral são imediatistas;

b) De incentivos - ocorre quando há espaço para o agricultor se comportar de forma oportunista, tornando-se um carona (free rider) buscando tirar vantagens apenas para si. Exemplo deste processo ocorre quando o cooperado comercializa a produção com terceiros em situação vantajosa, em detrimento aos compromissos assumidos com a cooperativa;

c) De portfólio - está atrelado ao primeiro problema, ou seja, horizonte de curto prazo e a dificuldade de acesso a crédito o que dificulta investimentos, para ampliar a participação na cadeia produtiva (industrialização, fixar marca entre os consumidores, entre outros). Assim, geralmente cooperativas ficam restritas a captação e processamento básico da produção;

d) De controle - pode ocorrer pelo fato das decisões estratégicas da cooperativa e o processo de acompanhamento e controle serem feitos pelo mesmo ator (o cooperado);

e) De influência - ocorre devido o processo de composição da diretoria executiva, uma vez que pode refletir mais os aspectos da articulação política do que a capacidade de gestão.

Zylberstajn (2005) com base na NEI aponta quatro questões estratégicas a serem trabalhadas pelas cooperativas para superar seus principais gargalos, ou seja, "os mecanismos de capitalização, o problema da fidelização do cooperado, a governança corporativa da cooperativa, e a internacionalização das organizações cooperativistas" (ZYLBERSTAJN, 2005, p. 56). 
A respeito da fidelização o autor observa que a cooperativa realiza seus investimentos a partir da expectativa e demanda do associado. Quando este comercializa a produção com outra empresa põe em risco a capacidade competitiva da cooperativa. Bialoskorski Neto (2005) lembra que atitudes egoístas podem ser atenuadas quando há alguma política de incentivo na cooperativa. O autor aponta que "o cooperado pode apresentar uma ação de oportunismo contratual, pelo fato de ser agente principal da mesma relação contratual e, frequentemente, poder objetivar seu próprio bem-estar em detrimento da eficiência da cooperativa" (BIALOSKORSKI NETO, 2005, p. 82). Tanto Bialoskorski Neto (2005) como Zylberstajn (2005) sugerem três formas de estimular fidelização do cooperado: a) os incentivos econômicos; b) o estabelecimento de bônus; e c) a elaboração de contratos para as transações, contendo direitos, obrigações e responsabilidades.

Para minimizar a prática do carona nas cooperativas, Pivoto, Finger e Waquil (2013), sugerem duas estratégias para minimizar o problema, ou seja, para reduzir o oportunismo dos cooperados. A primeira estratégia proposta é criar restrições aos benefícios coletivos, e a segunda criar incentivos que deem recompensa para os associados ativos e punições aos que não colaboram com o projeto coletivo. O autor propõe como estratégia "a fidelização por meio de preço, comunicação com o cooperado, contratos de obrigatoriedade de entrega, mecanismos de diferenciação de entrega e educação cooperativista" (PIVOTO; FINGER; WAQUIL, 2013, p. 112).

Esses mecanismos muitas vezes são necessários para equilíbrio da cooperativa, pois os custos acabam onerando aqueles que efetivamente comercializam via a cooperativa. Segundo os autores essa é uma das estratégias que as cooperativas precisam desenvolver melhor. Aqui se expressa o dilema secular enfatizado por Franz Oppenheimer ainda em 1896, segundo Búrigo (2010), quando publicada A Lei da Transformação, acentuado, especialmente pela ampliação da monetarização da vida social dos agricultores e da sociedade em geral pela expansão do espírito da competição e da acumulação privada:

[...] o destino das cooperativas é o fracasso, seja através de sua bancarrota, seja do seu sucesso econômico. No caso do sucesso, os sócios fundadores 'privatizarão' sucessivamente os lucros, [...] a cooperativa vira uma sociedade de capital e os sócios, capitalistas coletivos. [...] Entre a bancarrota e o caminho capitalista só existem períodos de transição temporários, intermediados pela auto exploração (BÚRIGO, 2010, p. 48). 
O desafio posto é demonstrar que, diferente da empresa, a relação do agricultor com a cooperativa não acaba no ato comercial, ou no pagamento do produto vendido ou do serviço prestado, mas que há uma série de benefícios econômicos e sociais que precisam ser levados em conta para no final se analisar qual de fato a participação na cooperativa foi o melhor resultado.

\section{Metodologia}

O presente trabalho se baseou em um estudo de caso, sendo para tal utilizada a estratégia da pesquisa exploratória por meio da utilização de ferramentas quanti-qualitativas. Os trabalhos foram realizados no Projeto de Assentamento Rio Paraíso (P. A. Rio Paraíso), no município de Jataí - Goiás. A escolha ocorreu em função da existência de conhecimento anterior do pesquisador com a região e dos seguintes aspectos: o tipo de ocupação, a estrutura fundiária, os sistemas produtivos, o número de unidades familiares e as organizações socioeconômicas da agricultura familiar predominantes na área. O município de Jataí situa-se na microrregião sudoeste goiano ${ }^{2}$, região de grande produção agropecuária com predomínio da produção de commodities agrícolas, principalmente soja e milho e a criação de aves e suínos por meio da integração com agroindústrias. De acordo com o Censo Agropecuário, o município de Jataí possuía em seu território 1.585 estabelecimentos rurais dos quais, conforme IBGE (2015), 678 são da agricultura familiar. Com base nos dados do Instituo Nacional de Colonização e Reforma Agrária (INCRA), dentre os estabelecimentos rurais que trabalham em regime de economia familiar, 438 eram formados por assentamentos com uma área reformada de 13.906 hectares o que representa em média 31,75 hectares por família assentada.

O Projeto de Assentamento Rio Paraíso encontra-se próximo à BR 060, na altura do quilometro 448, em torno de $30 \mathrm{~km}$ da sede do município de Jataí/Goiás. Conforme o INCRA sua capacidade é para 176 unidades familiares, sendo efetivamente assentadas 173 famílias. Conforme levantamento feito junto às lideranças locais, os atores institucionais e visitas in loco, atualmente, existem em torno de 140 unidades familiares que exploram estes lotes. Há vários agricultores que possuem dois ou mais lotes. Os lotes possuem entre 25 a 38

\footnotetext{
${ }^{2}$ Microrregião que faz parte da região Sul do Estado de Goiás 
hectares, na média de 31,6 hectares cada. No assentamento encontra-se um pequeno povoado, na qual ficam localizados entre outros, a Cooperativa Mista Agropecuária do Rio Doce (COPARPA).

As informações quanti-qualitativas foram obtidas por meio da aplicação de questionário com roteiro pré-definido, a fim de buscar informações sobre as questões sociais, econômicas, culturais e políticas que diretamente diziam respeito às estratégias da agricultura familiar no tocante a inserção no mercado. Para efeito de análise utilizou-se as seguintes características: 1) processo de comercialização; e 2) processo de comercialização e a influência dos mercados institucionais. Os públicos entrevistados foram: 1) agricultores familiares; 2) dirigentes sindicais; 3 ) dirigentes de associação com sede na comunidade do assentamento; 4) dirigentes da cooperativa agropecuária, com sede no assentamento, responsáveis pela gestão e área de comercialização; 5) dirigentes da Central de Cooperativas a qual a cooperativa é filiada; 6) responsável pelo posto de atendimento da Empresa de Assistência Técnica e Extensão Rural (EMATER) no assentamento; 7) responsável pela Divisão de Agricultura Familiar da Secretaria de Agricultura do Município de Jataí.

Quanto aos instrumentos de pesquisa para a consulta aos agricultores familiares foi elaborado um questionário estruturado. Em relação aos atores institucionais, para captar suas ponderações, foi elaborado outro questionário semiestruturado para servir como instrumento de apoio e roteiro para as entrevistas. Foram consultadas 103 famílias, sendo que dessas 95 eram filiadas a cooperativa. Para fins de preservar identidade das pessoas, as fontes das falas e entrevistas transcritas a seguir foram codificadas.

\section{Resultados e discussões}

O assentamento Rio Paraíso apresenta como principais atividades produtivas para fins comerciais, a produção de commodities (soja e milho) e de leite bovino. A soja é produzida por $94 \%$ das unidades familiares e o milho atinge $82 \%$ dos estabelecimentos. Já a atividade leiteira está presente em 39\% das famílias, das quais 38\% o leite é a atividade principal (Tabela 1). 
Tabela 1 - Atividade comerciais* (\%) das famílias do assentamento Rio Paraíso - GO, 2014.

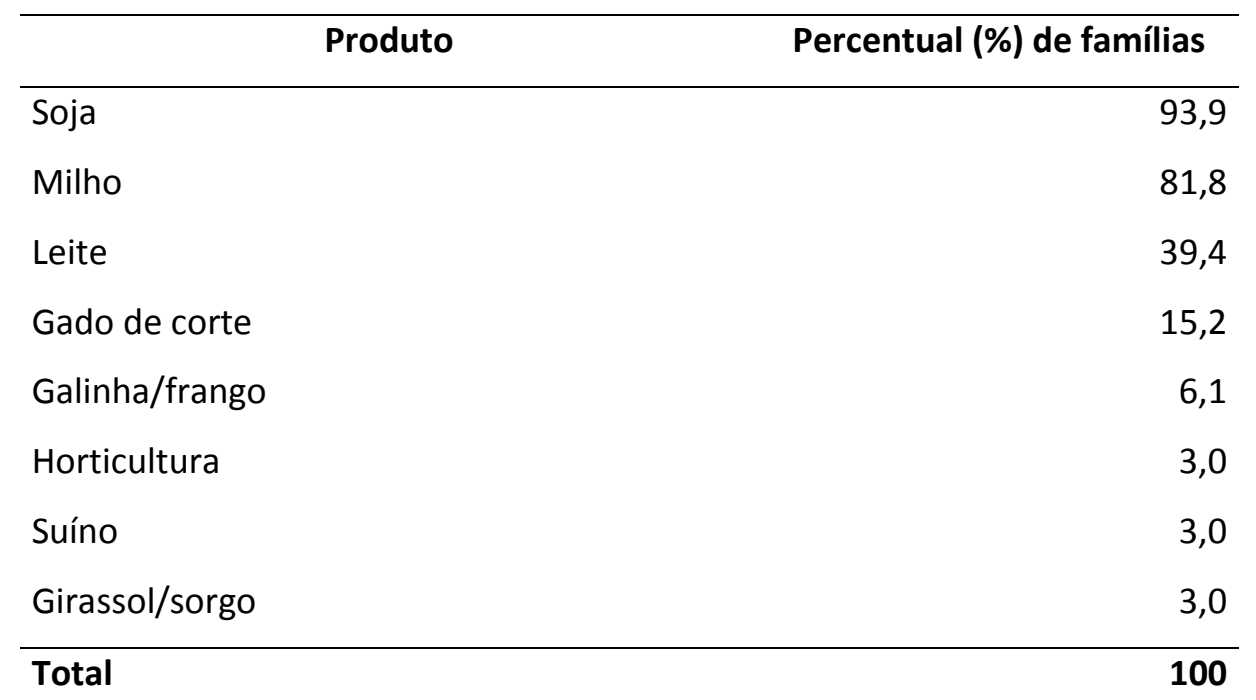

Fonte: Elaborado pelos autores a partir de dados de campo coletados no ano de 2014. *O total de unidades familiares e percentual não corresponde com a soma pelo fato da mesma unidade familiar atuar com diversos produtos.

Quanto ao papel e importância da cooperativa no processo de comercialização. Na pesquisa 95 famílias afirmaram estar filiada a alguma cooperativa, o que representa 92,2\% do universo pesquisado. Das famílias ligadas às cooperativas, $97,9 \%$ são associadas à COPARPA, 26,3\% estão ligadas a COMIGO e 2,1\% estão filiadas a COOPAF. O foco principal da análise desta pesquisa foi a COPARPA pelo fato de ter próximo a $100 \%$ das famílias cooperativadas (Tabela 2).

Quanto aos canais de comercialização, 94\% das unidades familiares que produzem soja e $62 \%$ das famílias que atuam com leite, vendem estes produtos por meio das cooperativas. Por outro lado, apesar de $88 \%$ dos estabelecimentos comercializarem $82 \%$ da produção de milho diretamente para empresas privadas, os agricultores familiares declararam o desejo de mudar este processo, pois atualmente $50 \%$ das famílias já vendem parte da produção via cooperativa, e sinalizaram que possuem demanda de infraestrutura de secagem e armazenagem dos grãos. Apesar da maioria dos agricultores familiares terem declarado preferência em comercializar sua produção por meio da cooperativa, suas estratégias são de curto prazo, focalizam o resultado imediato, ou seja, buscam o melhor resultado de momento e mudam o canal de acesso ao mercado basicamente em função do melhor preço. 
Tabela 2 - Cooperativas com respectiva quantidade e percentual de cooperados

\begin{tabular}{lrr}
\hline \multicolumn{1}{c}{ COOPERATIVAS } & Quantidade Cooperados & Cooperados (\%) \\
\hline COPARPA & 93 & 97,9 \\
COMIGO & 25 & 26,3 \\
COOPAF & 2 & 2,1 \\
\hline TOTAL & $\mathbf{9 5}$ & $\mathbf{1 0 0}$
\end{tabular}

Fonte: Elaborado pelo autor a partir de dados de campo coletados no ano de 2014.

*O total de unidades familiares cooperativadas e respectivo percentual não corresponde com a soma pelo fato de existirem pessoas associadas a mais de uma cooperativa.

Essa situação pode ser constatada pelas respostas sobre qual o principal fator de escolha do canal de comercialização, e qual a principal motivação para mudar de canal. A principal resposta para ambas às questões foi o fator preço apontado por $64 \%$ das unidades familiares. Zylbertajn (2005) destaca que é comum os agricultores terem interesses de curto prazo, pois a maioria é imediatista, o que explicaria esta escolha. Sob essa perspectiva, pondera-se que há necessidade de a cooperativa aumentar sua competitividade para se tornar mais atrativa como agente de comercialização. Nas atividades produtivas onde a cooperativa atua com mais força, como no caso do leite, ela consegue atenuar a relação comercial local, forçando as empresas a pagarem preços acima dos praticados pela cooperativa para garantirem sua participação na captação do produto no assentamento. No caso da soja, a atuação da cooperativa é decisiva para a agregação de valor, propiciando ganhos acima do preço de mercado devido à destinação do produto para a política governamental que estimula a venda do produto para fins de produção de biodiesel (Programa Nacional de Produção e uso do Biodiesel - PNPB).

Por outro lado, esta conjuntura levanta a preocupação quanto à dependência da cooperativa em relação às políticas públicas para ser competitiva. Os resultados diferenciados, com preços maiores que os do mercado que ela consegue para os agricultores são decorrentes, principalmente, à atuação no programa biodiesel e em menor escala aos mercados institucionais. Essa situação, que a princípio se apresenta "competitiva", demonstra que a cooperativa e os agricultores estão de certa forma dependentes desses estímulos governamentais, podendo haver grande dificuldades para a organização concorrer caso haja algum retrocesso nesses programas de estimulo à comercialização. Entre os filiados à cooperativa, $81 \%$ a utilizam como meio para comercializar a maior parte da 
produção no mercado, sendo que $27 \%$ dessas unidades familiares vendem mais de $80 \%$ dos alimentos produzidos por meio de cooperativa e outras $54 \%$ de famílias repassam entre 50 e $80 \%$ das mercadorias (Tabela 3).

Tabela 3 - Unidades familiares e percentuais da produção comercializada por meio
de cooperativa

\begin{tabular}{lrr}
\hline $\begin{array}{c}\text { Comercialização da produção via } \\
\text { cooperativa }\end{array}$ & Unidades familiares & Percentual (\%) \\
\hline Até $20 \%$ & 9 & 9,5 \\
Entre 20 e 50\% & 9 & 9,5 \\
Entre 50 e 80\% & 51 & 53,7 \\
Acima de 80\% & 26 & 27,4 \\
\hline Total & $\mathbf{9 5}$ & $\mathbf{1 0 0}$ \\
\hline
\end{tabular}

Fonte: Elaborado pelo autor a partir de dados de campo coletados no ano de 2014.

Segundo os agricultores entrevistados, estes percentuais não são maiores devido ao fato da COPARPA, não ter condições de investir em infraestrutura de armazenagem do milho e numa indústria processadora deste cereal. Essa situação fica evidente nas respostas de $88 \%$ das unidades familiares que vendem $82 \%$ do milho para as empresas cerealistas, alegando como principal motivo à falta de infraestrutura de armazenagem da cooperativa.

A partir da ótica dos dirigentes da COPARPA, pode-se apresentar um segundo motivo da comercialização do milho diretamente com as empresas. De acordo com o dirigente, o principal papel da cooperativa é a prestação de serviços, e nesse sentido, ela apenas intermedia a comercialização dos produtos se esta operação for competitiva e conseguir trazer benefícios econômicos para os cooperados. Na percepção destes, isto ocorre no caso da venda aos mercados institucionais.

Destaca-se neste caso, o problema dos custos de transação, apontados por Slangen, Locks e Slangen (2008) com base na tese de Coase (1988), são os custos de utilização dos mecanismos de mercado que dependem da natureza do bem, o tipo de operação e a forma em que esta é conduzida. Entre os seis tipos de investimentos específicos na transação sugeridos por Williamson (1975), para medir a importância das especificidades dos ativos, constata-se que dois afetam diretamente a realidade da COPARPA.

O primeiro é relativo à marca - fica evidente a fragilidade da cooperativa, sua 
capacidade de investir e ter retorno sobre os recursos investidos para a divulgação da marca, pois os volumes de produção são relativamente pequenos. Naquele momento, o volume a ser industrializado e comercializado não tornava economicamente viável a criação e a divulgação de uma marca própria. Para chegar a um ponto ótimo entre os custos e benefícios a cooperativa utiliza a estratégia de terceirização do processo industrial, contratando a prestação de serviços de industrialização de outra cooperativa e empresas da região. Tática essa que gera economia ao se evitar a imobilização de recursos financeiros, mas expõe uma fragilidade, que é a vulnerabilidade quanto às garantias de continuidade desse serviço a médio e longo prazo. Este procedimento fragiliza a cooperativa no sentido de não poder aumentar o leque de clientes, mantendo-se basicamente restrito aos mercados institucionais que possuem contratos de entrega de curto e médio prazo.

A segunda especificidade está relacionada ao tempo - trata-se de produtos perecíveis, que são afetados em sua qualidade pelo tempo, e de produtos sazonais os quais podem ocorrer em abundância em um período do ano, sendo mais escassos nos outros. Esta especificidade recai especialmente sobre os três produtos principais dos assentados. 0 maior impacto da perecibilidade está relacionado ao leite, que necessita ser processado em curtíssimo prazo. A questão sazonalidade reflete-se principalmente na produção de milho, pelo fato da cooperativa não ter condições de promover a secagem e armazenagem do grão para o associado, deixando assim a mercê do mercado, ou seja, vulnerável a atuação das empresas e indústrias que operam na região.

Por outro lado, também se evidencia que a cooperativa encontra dificuldades de intervenção no mercado do milho, apresentando principalmente problemas de horizonte e de portfólio. Zylbertajn (2005), a respeito dos problemas de horizonte e de portfólio aponta que o primeiro geralmente se apresenta em projetos de longo prazo, pois é comum os cooperados terem interesses de curto prazo, pois na sua maioria são imediatistas, dessa forma as propostas de investimentos com retorno de longo prazo enfrentam dificuldades para sua aprovação. O segundo, de portfólio, está atrelado ao primeiro problema, ou seja, horizonte de curto prazo e a dificuldade de acesso ao crédito dificulta a realização de investimentos para ampliar a participação na cadeia produtiva (industrialização, a marca, entre outros). Dessa forma a cooperativa se restringe basicamente a captação da produção.

O caráter imediatista dos agricultores familiares associados merece um comentário 
adicional. Este comportamento pode ser explicado devido à restrita margem de manobra financeira dos agricultores, que quase sempre não possuem reservas econômicas que permitem estratégias de longo prazo. Adicionalmente deve-se acrescentar o fato parte de que partes dos ativos oriundos da comercialização estão diretamente ligados à mercantilização para sobrevivência devido à necessidade premente de dinheiro no curto prazo.

$\mathrm{Na}$ comercialização do leite a cooperativa recebe a produção de $62 \%$ das unidades familiares, enquanto que $31 \%$ comercializam com empresas que atuam na região, destacando-se como principal motivo o preço pago ao produto. Novamente apresenta-se um problema de portfólio, pois a cooperativa processa parte da produção por meio de outra cooperativa. Para este leite que é processado, transformado em leite pasteurizado e derivados como (queijo, iogurte, requeijão), têm sido comercializados nos mercados institucionais onde a COPARPA tem conseguido remunerar melhor os agricultores. 0 problema a ressaltar é o fato desse mercado ainda ser pequeno, consumindo apenas uma pequena parte da produção total. É importante destacar a existência de mais agricultores interessados em buscar outros canais, fora da cooperativa, motivados principalmente pelo preço. Essa situação ainda não ocorre com maior intensidade devido à pequena escala de produção destes agricultores.

Apesar das dificuldades na comercialização do milho e do leite, na comercialização da soja a COPARPA consegue incidir com força, pois $94 \%$ das famílias vendem a oleaginosa por meio da organização a qual estão filiados. A expressão da cultura da soja induz a concluir sobre a preferência dos agricultores familiares, está diretamente conectado com a facilidade de comercialização.

Conterato (2004) ao analisar os agricultores na Região do Alto Uruguai (RS) chamou de "sojicização", na medida em que a soja se apresenta como o carro chefe da modernização e mercantilização da agricultura, inclusive familiar. A facilidade de comercialização se deve ao preço diferenciado que a cooperativa consegue obter ao produto por meio da inserção ao Programa Nacional de Produção e Uso do Biodiesel (PNPB), com empresas que possuem o Selo Combustível Social (SCS). Neste ponto destaca-se o papel das instituições (nesse caso, a cooperativa), fruto da organização político-sindical dos próprios agricultores familiares, fortalecendo a sua ação coletiva, e que através da associação e da cooperativa consegue promover significativos avanços econômicos e sociais para os assentados. 
Entre os quatro níveis das instituições: capital social, economia dos direitos de propriedade, custos de transação econômica e estruturas internas e externas de incentivo, apontadas na nova economia institucional por Williamson (1975), nota-se com maior força a presença da estrutura de incentivos. Neste nível devido às mudanças contínuas, refletindo a realidade dos mercados e a força dos atores envolvidos no processo, a ação conjunta e coordenada das entidades tem propiciado ganhos relativamente satisfatórios aos assentados, principalmente no que tange ao processo de comercialização e acesso a mercados com preços diferenciados.

Do universo de 103 unidades familiares pesquisadas, 59 famílias atuam nos mercados institucionais PAA e PNAE. Para 95\%, a cooperativa foi imprescindível para que conseguissem vender os alimentos neste mercado (Tabela 4). As principais motivações apontadas pelos agricultores familiares para atuarem nos mercados institucionais, foram o preço em 67\% das unidades familiares, e devido à cooperativa ter apresentado a oportunidade de comercialização em $44 \%$ das respostas. Entre os que indicaram o preço como principal motivo, ainda há $11 \%$ que também apontaram a garantia de comercialização como aspecto relevante.

Para aqueles que atuam nos mercados institucionais com produtos derivados do leite e milho, conforme informações dos agricultores e dirigentes da cooperativa, são distribuídas sobras financeiras da cooperativa anualmente. Essa prática da distribuição de sobras aos associados, aliado ao bom preço pago e a garantia de mercado para os produtos tem animado os cooperados a buscar com mais intensidade essa opção de venda. No entanto, para ampliar sua participação nos mercados institucionais, a cooperativa sofre dos problemas já anteriormente diagnosticados. Atualmente ela terceiriza a transformação da matéria prima, basicamente o leite e o milho, em produtos acabados para atender os contratos de venda para o PAA e PNAE. Constata-se que os mercados institucionais, apesar da pequena participação na receita total gerada na produção, são importantes na medida em que criaram alternativas de comercialização, estimulando a venda da produção e fortalecimento da ação coletiva por meio de organização socioeconômica dos agricultores familiares. 
Tabela 4 - Percentual de unidades familiares que vendem para os mercados institucionais e nível de importância da cooperativa no processo

\begin{tabular}{lrr|lrr}
\hline $\begin{array}{c}\text { Atua nos mercados } \\
\text { institucionais }\end{array}$ & $\begin{array}{c}\text { Unidades } \\
\text { familiares }\end{array}$ & $\begin{array}{c}\text { Percentual } \\
\text { (\%) }\end{array}$ & $\begin{array}{l}\text { A Cooperativa } \\
\text { é fundamental }\end{array}$ & $\begin{array}{r}\text { Unidades } \\
\text { familiares }\end{array}$ & $\begin{array}{r}\text { Percentual } \\
\text { (\%) }\end{array}$ \\
\hline Sim & 59 & 57,3 & Sim & 56 & 94,9 \\
Não & 44 & $\mathbf{4 2 , 7}$ & Não & 3 & 5,1 \\
\hline Total & $\mathbf{1 0 3}$ & $\mathbf{1 0 0}$ & Total * & $\mathbf{5 9}$ & $\mathbf{1 0 0}$ \\
\hline
\end{tabular}

Fonte: Elaborado pelo autor a partir de dados de campo coletados no ano de 2014.

*Refere-se aos agricultores que afirmaram comercializar para os mercados institucionais.

As cooperativas, mesmo apresentando algumas deficiências, possuem a confiança dos agricultores em relação à comercialização. Para 76\% dos entrevistados, ela vem tendo um desempenho ótimo ou bom, e ainda $75 \%$ afirmam, que de forma geral, a cooperativa melhorou a renda e condições de vida das famílias (Tabela 05).

Tabela 5 - Percentual de unidades familiares e o desempenho da cooperativa como canal de comercialização

\begin{tabular}{lrr}
\hline Desempenho da cooperativa como canal de & $\begin{array}{c}\text { Unidades } \\
\text { comercialização }\end{array}$ & \multicolumn{2}{c}{$\begin{array}{c}\text { Percentual (\%) } \\
\text { familiares }\end{array}$} & 37 & 38,9 \\
\hline Ótimo & 35 & 36,8 \\
Bom & 12 & 12,6 \\
Razoável & 2 & 2,1 \\
Ruim & 2 & 2,1 \\
Péssimo & 7 & 7,4 \\
NS/NR & 95 & $\mathbf{1 0 0 , 0}$ \\
\hline Total & 95 &
\end{tabular}

Fonte: Elaborado pelo autor a partir de dados de campo coletados no ano de 2014.

Pode-se dessa forma inferir que a maioria dos agricultores familiares comercializa seus produtos por meio de cooperativa, por entenderem ser a melhor opção, a fim de potencializar suas condições de acesso ao mercado.

\section{Considerações finais}

A maioria das famílias escolheu a cooperativa como canal de comercialização, sendo que $81 \%$ dos agricultores a utilizam como meio para comercializar a maior parte de sua 
produção. No entanto, o foco dos agricultores está na busca de uma maior remuneração, portanto, a decisão de vender por meio da cooperativa ou não depende do preço pago aos produtos. Um segundo aspecto a ressaltar são gargalos da cooperativa em relação à falta de infraestrutura física para armazenamento e processamento da produção. Muitas oportunidades comerciais são perdidas em função de não ter um local para secar e armazenar a produção de grãos, notadamente, o milho. Constata-se que há espaço para ampliar a participação da COPARPA como canal de comercialização, tanto de matéria prima como de subprodutos.

A cooperativa tem viabilizado o acesso às políticas públicas de estímulo a comercialização, como: o Programa Nacional de Produção e Uso de Biodiesel, o Programa de Aquisição de Alimentos e o Programa Nacional de Alimentação Escolar. No Biodiesel a participação da cooperativa chega a $94 \%$ da soja comercializada. Entretanto, fica evidente a dependência da cooperativa das políticas públicas, especialmente por conseguir resultados mais compensadores para os agricultores familiares quando atua no programa biodiesel, e nos casos em que consegue acessar os mercados institucionais. Essa "vantagem" demonstra dependência dos estímulos governamentais, podendo haver grande dificuldade para a organização no futuro, caso haja algum retrocesso nos programas públicos de estímulo à comercialização. Por outro lado, observou-se o papel relevante dos mercados institucionais para estimular o fortalecimento das organizações, incentivando a busca de novos mercados a partir dos resultados alcançados com as políticas públicas de estímulo a comercialização.

Os resultados demonstram a importância do cooperativismo para os agricultores familiares do assentamento Rio Paraíso, bem como apontam para os desafios que enfrenta no tocante a comercialização da sua produção.

\section{Referências}

BENECKE, D. W. Cooperação e desenvolvimento: o papel das cooperativas no processo de desenvolvimento econômico nos países do terceiro mundo. Porto Alegre: Coojornal; Recife: Assocene, 1980.

BIALOSKORSKI NETO, S. Estratégias e Cooperativas Agropecuárias: um ensaio analítico. In: BRAGA, M. J.; REIS, B. D. S. (Orgs.). Viçosa: UFV, DER. 2005. p. 77-101. 
BOTELHO FILHO, Flávio B. As portas de saída da pobreza e as estratégias da agricultura familiar para os negócios rurais. In: BOTELHO FILHO, F. B. (Org.). Agricultura familiar e desenvolvimento territorial: contribuições ao debate. Brasília, Centro de Estudos Avançados Multidisciplinares. Núcleo de Estudos Avançados. v. 5, n. 17, 2005. p. 131-139.

BOTELHO FILHO, F. B; VALENTE, A. L. Arranjos institucionais, organização dos produtores e redução dos custos de transação. In: SABOURIN, E. (Org.). Associativismo, cooperativismo e economia solidária no meio rural. Universidade de Brasília. Centro de Estudos Avançados Multidisciplinares. Núcleo de Estudos Avançados. Brasília, v. 6, n. 23, 2006. p. 113-121.

BUAINAIN, A. M. et al. Agricultura familiar e o novo rural. Sociologias, Porto Alegre: ano V, n. 10, jul./dez., 2003. p. 312-347.

. Brasília: IICA. Série desenvolvimento rural sustentável, v. 16, 2012. p. 121-159.

BÚRIGO, F. L. Finanças e solidariedade: cooperativismo de crédito rural solidário no Brasil. Chapecó: Argos, 2010.

CLARO, D. P.; SANTOS, A. C. D. O complexo agroindustrial das flores sob a ótica da economia dos custos de transação. Faculdade de Economia e Administração e Contabilidade de São Paulo, Caderno de Pesquisa em Administração, São Paulo, v. 1, n. 7, 2ㅇTrim., 1998.

COASE, R. H. The firm, the market and the law. Chicago: Chicago University Press, 1988.

CONTERATO, M. A. A mercantilização da agricultura familiar do Alto Uruguai/RS: um estudo de caso no município de Três Palmeiras. Dissertação (Mestrado - PGDR) - Universidade Federal do Rio Grande do Sul, Porto Alegre.

GOMES JUNIOR, N. N.; BOTELHO FILHO, F. B. O mercado institucional local e as oportunidades para a agricultura familiar de alimentos: agenda positiva para a construção da segurança alimentar e nutricional nos espaços urbanos. SOBER 470 Congresso. Porto Alegre, 2009.

GUANZIROLI, C. E.; DI SABBATO, A.; BUANAIN, A. M. Dez anos de evolução da agricultura familiar do Brasil: 1996-2006. RESR, v. 50, n. 2, Piracicaba, 2012. p. 351-370.

HELFAND, S. M.; PEREIRA, V. D. F. Determinantes da pobreza rural e implicações para as políticas públicas no Brasil. In: MIRANDA, C.; TIBURCIO, B. (Orgs.). A nova cara da pobreza rural: desafios para as políticas públicas. 2012.

Rio de Janeiro: IBGE, 2006. Disponível em: <www.ibge.gov.br>. Acesso em: 27 out. 2016.

INSTITUTO BRASILEIRO DE GEOGRAFIA E ESTATÍSTICA. IBGE. Censo agropecuário 2006. Disponível em: http://www.sidra.ibge.gov.br/bda/tabela/protabl.asp?c=1109\&z=p\&o=2\&i=P . Acesso em: 10 nov. 2015. 
MARQUES, V. P. M.; DEL GROSSI, M. E.; FRANCA, C. G. O Censo 2006 e a reforma agrária: aspectos metodológicos e primeiros resultados. Brasília: Ministério do Desenvolvimento Agrário, 2012.

NORTH, D. C. Institutions, institutional change and economic performance. Cambridge: Cambridge University Press, 1990.

PIVOTO, D. ; FINGER, M. I.; WAQUIL, P. O problema do carona nas cooperativas agropecuárias do Rio Grande do Sul. Revista de Política Agrícola, ano XXII, n. 4, out./dez., 2013. p. 109-122.

SCHNEIDER, S.; CASSOL, A. A agricultura familiar no Brasil, FIDA pobreza y desigualdade, Porto Alegre: RIMISP, 2013.

SLANGEN, L.; H. G; LOUCKS, L. A.; SLANGEN, A. H. L. Institucional economics and economic organization theory: an integrated approach. Wageningen Academic Publishers, The Netherlands, p. 431, 2008.

WILLIAMSON, O. E. Markets e hierarchies: analysis and antitrust implications. New York: Free Press, 1975.

ZYLBERSZTAJN, D. Estruturas de governança e coordenação do agribusiness: uma aplicação da nova economia das instituições. São Paulo: Universidade de São Paulo, 1995.

. Quatro estratégias fundamentais para cooperativas agrícolas. In: BRAGA M. J.; REIS, B. D. S. (Orgs.). Agronegócio cooperativo: reestruturação e estratégias. Viçosa: UFV, 2005. p. 55-76. 